STUDI

FRANCESI

\section{Studi Francesi}

Rivista quadrimestrale fondata da Franco Simone

171 (LVII | III) | 2013

FRANCO SIMONE E LA STORIOGRAFIA LETTERARIA -

Atti della giornata di studi nel centenario della nascita promossa dall'Accademia delle Scienze di Torino in collaborazione con «Studi Francesi» Torino - 24 maggio 2013

\title{
Aimé Césaire, Du fond d'un pays de silence...
}

\section{Emanuela Cacchioli}

\section{(2) OpenEdition \\ 1 Journals}

\section{Edizione digitale}

URL: http://journals.openedition.org/studifrancesi/2912

DOI: 10.4000/studifrancesi.2912

ISSN: 2421-5856

Editore

Rosenberg \& Sellier

\section{Edizione cartacea}

Data di pubblicazione: 1 dicembre 2013

Paginazione: 656-657

ISSN: 0039-2944

\section{Notizia bibliografica digitale}

Emanuela Cacchioli, «Aimé Césaire, Du fond d'un pays de silence... », Studi Francesi [Online], 171 (LVII I

III) | 2013, online dal 30 novembre 2015, consultato il 18 septembre 2020. URL : http://

journals.openedition.org/studifrancesi/2912 ; DOI : https://doi.org/10.4000/studifrancesi.2912

Questo documento è stato generato automaticamente il 18 settembre 2020.

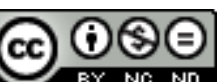

Studi Francesi è distribuita con Licenza Creative Commons Attribuzione - Non commerciale - Non opere derivate 4.0 Internazionale. 


\title{
Aimé Césaire, Du fond d'un pays de silence...
}

\author{
Emanuela Cacchioli
}

\section{NOTIZIA}

AIMÉ CÉSAIRE, Du fond d'un pays de silence..., Édition critique de «Ferrements» par Lilyan KESTELOOT, René HÉNANE et Mamadou Souley BA, Paris, Orizons, 2012, pp. 330.

1 Nel 2013, anno del centenario della nascita di Aimé Césaire, sono in programma numerosi convegni dedicati a uno dei maggiori autori caraibici, a cui seguiranno varie pubblicazioni. Tuttavia, l'attenzione nei confronti di Césaire non è mai scemata e l'edizione critica di Ferrements lo dimostra. La raccolta, pubblicata per la prima volta nel 1960, è stata ripresa alla fine del 2012 con un nuovo titolo ad indicare che non si tratta di una semplice riedizione, bensì di un'opera accresciuta di testi inediti e arricchita da un prezioso apparato critico e da commenti puntuali e rigorosi. L'opera è curata da Lilyan KESTELOOT, che è stata docente all'Università di Dakar; Souley BA, professore presso il medesimo ateneo e René HÉNANE, medico e saggista che, dopo aver incontrato Aimé Césaire nel 1986, ha dedicato numerosi studi al poeta martinicano. Si tratta di una collaborazione in cui sono coinvolti alcuni dei maggiori specialisti dell'opera di Césaire che avevano già lavorato insieme al volume Introduction à Moi, laminaire... di Aimé Césaire, pubblicato nel 2011 dalle edizioni L'Harmattan. Nelle intenzioni di Lilyan Kesteloot, $\mathrm{Du}$ fond d'un pays de silence vuole essere uno strumento in grado di offrire una chiave di lettura della poetica dello scrittore martinicano. In quest'ottica, risultano fondamentali le informazioni relative al contesto storico-culturale nel quale le poesie sono maturate: «Lorsque c'est un auteur engagé dans un combat vital, comme l'est en effet Aimé Césaire, il nous semblerait inexcusable de retenir des informations dont nous avons la certitude qu'elles éclairent sa poésie et confortent son aventure existentielle» (p. 8). Nella parte introduttiva del volume, è stata riprodotta una lettera che Césaire indirizza alla stessa Lilyan Kesteloot, in cui le spiega il valore delle parole, intese come forza 
vitale, delle immagini (in quanto lato nascosto e potenziale degli oggetti) e del ritmo, ossia di quell'aspetto che è anteriore alla parola e che struttura il componimento poetico. Sempre nella prima parte del volume, troviamo una sezione dedicata al contesto storico e letterario in cui si definisce Ferrements un'opera poetica spesso dimenticata o relegata in uno spazio angusto a causa del suo ermetismo. Lo stesso Césaire la considera un «bilancio provvisorio». La raccolta, infatti, riunisce una serie di componimenti scritti tra il 1945 e il 1960 in un periodo segnato da eventi importanti della vita privata, letteraria e politica, quali l'elezione a sindaco di Fort-de-France, l'attività all'Assemblée Nationale a Parigi, la rottura con il partito comunista nel 1956 e la fondazione del partito progressista. Si tratta, dunque, di anni fondamentali nella sua esistenza, ma anche di una fase in cui si succedono momenti di crisi. Da Ferrements emergono infatti la disillusione e la sofferenza, espresse attraverso la violenza delle immagini e l'ermetismo. La raccolta, che si caratterizza come un itinerario mentale e psicologico dell'autore, riprende le tematiche a lui più care: la rivolta radicale contro il razzismo e contro l'oppressione dell'Occidente, il richiamo al continente nero, il peso della schiavitù, la passività degli attuali discendenti confinati in isole senza avvenire. $\mathrm{Al}$ contesto storico-letterario, segue un dossier genetico che ripercorre le tappe di pubblicazioni dei singoli componimenti. La sezione dedicata ai testi fornisce al lettore una versione delle singole poesie di Ferrements, accompagnate dalle indicazioni relative alle diverse edizioni, dalle varianti e da un lungo commento critico e linguistico.

Nella seconda parte del volume, sono, invece, riprodotte alcune poesie apparse su riviste o declamate in pubblico in occasione di particolari avvenimenti e raccolte, per la prima volta, in volume. Al termine della sezione sono stati inseriti quattro componimenti del tutto inediti. A conclusione del volume è posto il discorso che Aimé Césaire ha pronunciato all'Assemblée Nationale il 29 settembre 1982. Vengono fornite al lettore due versioni: la trascrizione e la riproduzione fotografica del manoscritto redatto dallo stesso Césaire e donato a Lilyan Kasteloot. L'edizione critica di Ferrements si presenta, dunque, come uno strumento prezioso rivolto ad un pubblico eterogeneo che può accedere ad un'opera difficile e pertanto ancora poco letta. 